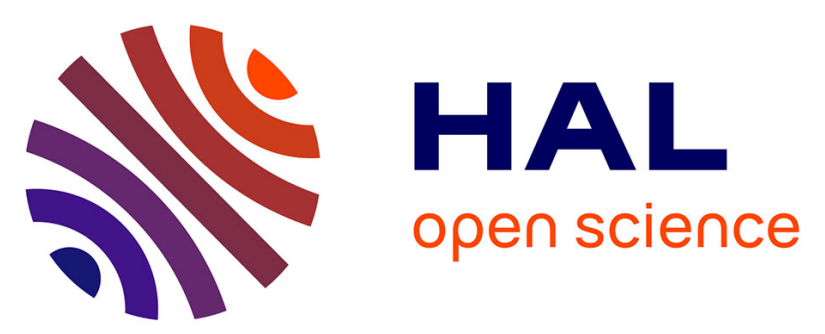

\title{
Uncertainty quantification of leakages in a multistage simulation and comparison with experiments
}

Cosimo Maria Mazzoni, Richard Ahlfeld, Budimir Rosic, Francesco Montomoli

\section{To cite this version:}

Cosimo Maria Mazzoni, Richard Ahlfeld, Budimir Rosic, Francesco Montomoli. Uncertainty quantification of leakages in a multistage simulation and comparison with experiments. 16th International Symposium on Transport Phenomena and Dynamics of Rotating Machinery, Apr 2016, Honolulu, United States. hal-01891325

\section{HAL Id: hal-01891325 \\ https://hal.science/hal-01891325}

Submitted on 9 Oct 2018

HAL is a multi-disciplinary open access archive for the deposit and dissemination of scientific research documents, whether they are published or not. The documents may come from teaching and research institutions in France or abroad, or from public or private research centers.
L'archive ouverte pluridisciplinaire HAL, est destinée au dépôt et à la diffusion de documents scientifiques de niveau recherche, publiés ou non, émanant des établissements d'enseignement et de recherche français ou étrangers, des laboratoires publics ou privés. 


\title{
Uncertainty quantification of leakages in a multistage simulation and comparison with experiments
}

\author{
C. M. Mazzoni ${ }^{1 *}$, R. Ahlfeld $^{2}$, B. Rosic $^{1}$, F. Montomoli $^{2}$
}

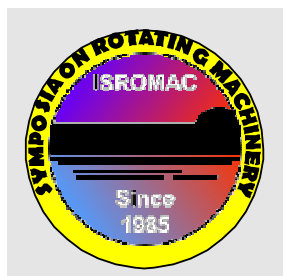

ISROMAC 2016

International

Symposium on Transport

Phenomena and Dynamics of

Rotating Machinery

Hawaii, Honolulu

April 10-15, 2016

\begin{abstract} random variation of the clearance height has not been investigated before. of the turbine blades. pressure turbines.

\author{
Keywords \\ Uncertainty Quantification — Tip Leakage — CFD \\ ${ }^{1}$ Department of Engineering Science, University of Oxford, United Kingdom \\ ${ }^{2}$ Department of Aeronautics, Imperial College of London, United Kingdom \\ *Corresponding author: cosimo.mazzoni@eng.ox.ac.uk
}

The present paper presents a numerical study of the impact of tip gap uncertainties in a multistage turbine. It is well known that the rotor gap can change the gas turbine efficiency but the impact of the

In this paper the radial seals clearance of a datum shroud geometry, representative of steam turbine industrial practice, was systematically varied and numerically tested. By using a Non-Intrusive Uncertainty Quantification simulation based on a Sparse Arbitrary Moment Based Approach, it is possible to predict the radial distribution of uncertainty in stagnation pressure and yaw angle at the exit

This work shows that the impact of gap uncertainties propagates radially from the tip towards the hub of the turbine and the complete span is affected by a variation of the rotor tip gap. This amplification of the uncertainty is mainly due to the low aspect ratio of the turbine and a similar behavior is expected in high

\section{INTRODUCTION}

In order to accommodate rotor to casing relative movement during turbine operation, circumferential inlet and exit shroud cavities must be formed. These necessary alterations in the overall flow path geometry significantly modify the main blade flow field. All reported works (i.e. Wallis [1], Pfau et al. [2], Rushton [3], Giboni et al. [4], Metzger and Rued [5-6], Anto et al. [7]) show the highly threedimensional nature of the flow in the cavities and the complex interaction between the leakage flow and the main passage flow. The cavities are fed by mainstream fluid and the flow inside the cavities is influenced by the blade-to-blade pressure field from the upstream and the downstream blade row and secondary flow structures from the upstream blade row (passage vortex, wakes, etc.). The presence of the shroud cavities, the mixing process when the leakage flow re-enters the mainstream, and the influence of leakage flow on the downstream blade row flow field all cause additional losses.

Shroud leakage loss mechanisms have been investigated by many authors. Traupel [8], Denton and Johnson [9], Denton [10], Gier et al. [11], Rosic and Denton [12], Rosic et al. [13], all tried to quantify these losses. However, the loss-generating mechanisms are highly dependent on the particular shroud and stage geometry, therefore it is difficult to develop universal design rules and to correlate different geometrical and operational turbine parameters to generic shroud design. A map of the possible turbine efficiency changes caused by different shroud modifications was obtained by Rosic et al. [14-15] who investigated the influence of each geometric parameter on the mainstream aerodynamics. The intention was to summarize these effects and to highlight efficiency trends that can be used by turbine designers as guidelines for their particular shroud geometry rather than to create universal design rules.

Finally, blade tip clearance changes during operation due to rotor unbalances, dynamic deformations and blade vibrations may have a huge impact on the safety, the lifetime and the energy efficiency of turbo machines. Thus, the increasing need for reliability in gas turbine design, both for power generation and aero-propulsion (Fadlun et al. [16]), requires tools that are able to include the strong variability due to manufacturing tolerances, assembly process and in service operations in the design system [17]. The question arising in recent years is how to take into account these features with their associated aleatory distribution. Bunker [18] applied a Monte Carlo simulation to study the impact of geometrical variations on HP components. The author showed that there is a wide range of parameters that can vary and their relative impact on the component life is different. Manufacturing variations can reduce the nozzle life by $33 \%$. A stochastic study on statistical variations introduced by in service degradation of the rotor tip was studied by [19]. The authors proved that the tip heat transfer is strongly influenced by the stochastic distribution of fillet radius and tip gap. The study has shown that is crucial to use an uncertainty quantification approach in hot streak migration predictions. A summary of the current state of UQ for aircraft engines can be found in [20].

Most of the uncertainty studies in literature have been obtained in simplified geometries. The study of Bunker [18], for example, was based on a flat plate assumption. More recently some studies have considered the impact or real geometries [19, 21-27]. However it is not clear how uncertainty is propagating in a flow. Carnevale et al. [21] have shown that the impact of uncertainty is modulated in a channel assuming a 
"transitional" like behavior. For this reason in this work we decided to simulate a multistage HP steam turbine to evaluate how the impact of uncertainty on seals clearance is affecting the downstream stages and is redistributing in the span-wise direction.

\section{THE MODEL TURBINE AND EXPERIMENTAL METHODS}

The experiments were carried out by Rosic [28] using a low speed multistage air turbine that was designed to represent the first few stages of a high pressure steam turbine (Fig.1). Atmospheric air enters the inlet section radially and passes through a flow straightener before entering the turbine. Air is drawn through three turbine stages by a fan downstream of the turbine. Both stator and rotor blades were shrouded. The operating point, determined by the flow coefficient and rotational speed, is set by the fan power and dynamometer brake. The flow coefficient $\mathrm{v}_{\mathrm{x}} / \mathrm{U}$ is calculated using the axial velocity at turbine inlet, which is measured indirectly using a mass flow measurement in the exhaust section and a density measurement at inlet.

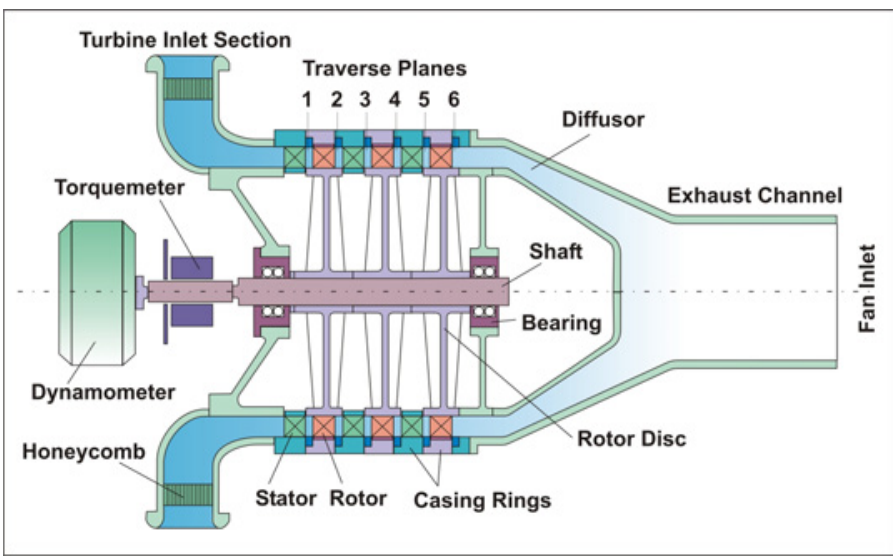

Fig. 1. Schematic of model turbine

Experiments were performed on $50 \%$ reaction blading at the design operation condition $(\phi=0.384)$. The key rig geometrical and operational parameters are presented in Tab.1. The blade parameters are taken at blade mid-height. The blading was designed to represent typical high pressure steam turbine conditions, and all parameters satisfy that condition. Only the Reynolds number, based on exit velocity and true chord, is significantly lower than that in a real turbine.

The rotor shroud cavities geometry and sealing arrangement under scrutiny is described in Figure 2. This configuration is representative of commercial turbine design as it allows for the axial movement of the rotor shaft relative to the casing. The shroud forms a radial clearance of $3 \mathrm{~mm}$ with the casing. Using two approximately $0.75 \mathrm{~mm}$ clearance radial seals resulted in an over-shroud leakage flow of approximately $2 \%$. A representation of the three stages experimental turbine is reported in Fig. 3.

To investigate the time-mean flow of the main passage, traverses were conducted using a five hole pneumatic probe. The properties were measured by performing full-span area
Table 1. Turbine Geometrical and Operational Parameters

\begin{tabular}{|c|c|c|}
\hline Design operating point data & & \\
\hline Flow Coefficient $\phi$ & \multicolumn{2}{|c|}{0.384} \\
\hline Stage Loading $\Psi=\Delta \mathrm{h}_{0} / \mathrm{U}^{2}$ & \multicolumn{2}{|c|}{1.0} \\
\hline Design Speed [rpm] & \multicolumn{2}{|c|}{830} \\
\hline Inlet Mach Number & \multicolumn{2}{|c|}{0.045} \\
\hline Inlet/Outlet Total Pressure [Pa] & 100465.4 & 75545.5 \\
\hline Inlet/Outlet Total Temperature [K] & 300 & 279 \\
\hline Number of Stages & \multicolumn{2}{|c|}{$\frac{1}{3}$} \\
\hline Inter Blade Row Spacing [mm] & \multicolumn{2}{|c|}{25} \\
\hline Blade Height h [mm] & \multicolumn{2}{|c|}{75} \\
\hline Mid-span Radius [mm] & \multicolumn{2}{|c|}{462.5} \\
\hline Hub to Tip Ratio & \multicolumn{2}{|c|}{0.85} \\
\hline Blade parameters & Stator & Rotor \\
\hline Blade Number & 40 & 38 \\
\hline True Chord 1 [mm] & 89.73 & 105 \\
\hline Aspect Ratio h/l & 0.836 & 0.714 \\
\hline Pitch to Chord Ratio & 0.81 & 0.728 \\
\hline Reynolds Number $^{(1)}$ & $2.53 \cdot 10^{5}$ & $2.97 \cdot 10^{5}$ \\
\hline
\end{tabular}

(1) based on true chord and exit velocity

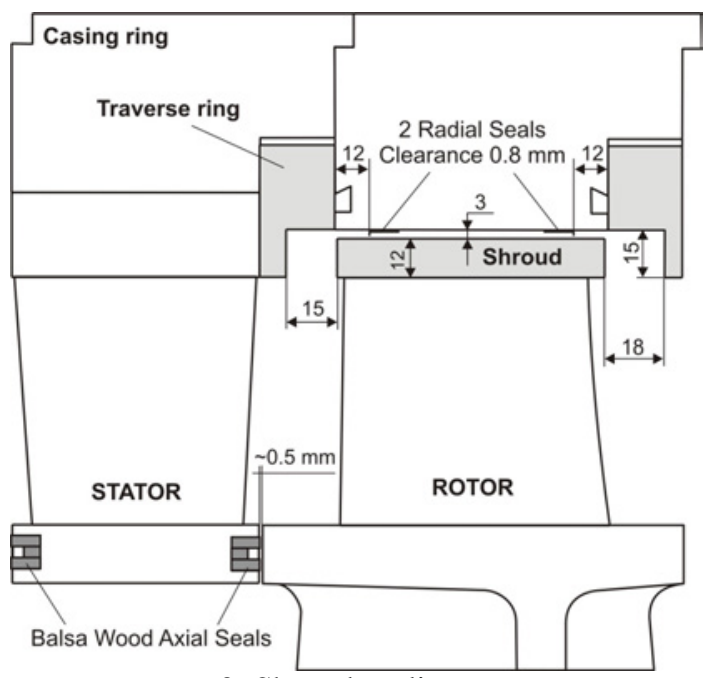

Fig. 2. Shroud sealing arrangement

traverses over one blade pitch at an axial distance of $6 \mathrm{~mm}$ and $17 \mathrm{~mm}$ downstream of the stator and rotor trailing edge tip respectively (Fig. 1). The traverse grid was 37 x 37 uniformly spaced points in both radial and pitch-wise directions. A detailed description of the experimental setup is reported in [28].

\section{TBLOCK DESCRIPTION}

TBLOCK is a multi-block structured grid solver developed by John Denton [29]. This is a steady or unsteady RANS solver and uses the finite volume method, with the explicit SCREE scheme [30] for steady simulations and dual-time stepping method for unsteady calculations. Turbulence is modelled using a mixing length approach. Laminar to turbulent boundary layer transition can be modelled by assuming a laminar boundary layer up to a specified point on each blade and end-wall surface and a turbulent one downstream. The mixing plane approach allows reversed flow across the mixing plane, which may occur near the end-walls close to the leakage cavities. To accelerate convergence multigrid and spatially varied time steps are used. 


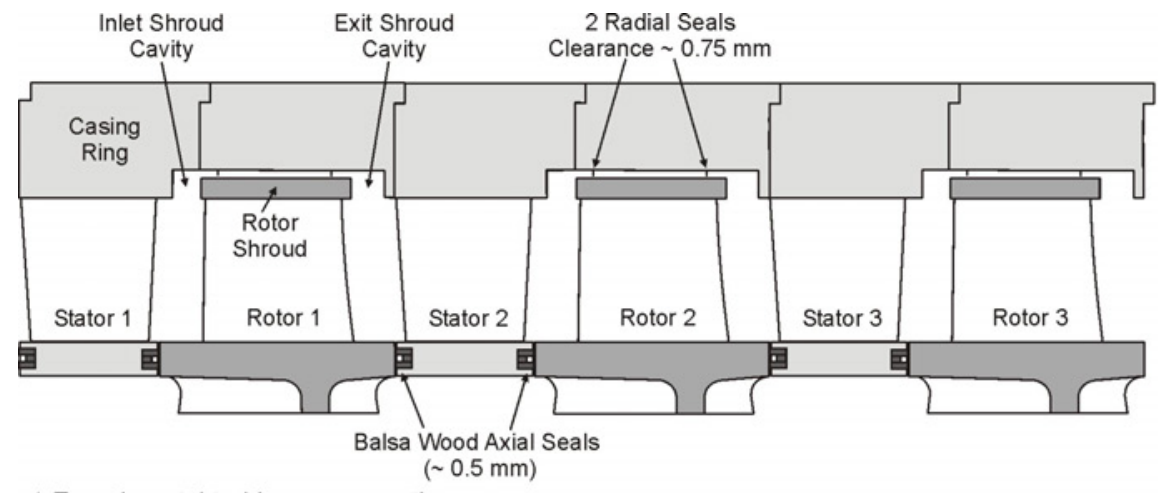

a) Experimental turbine cross-section

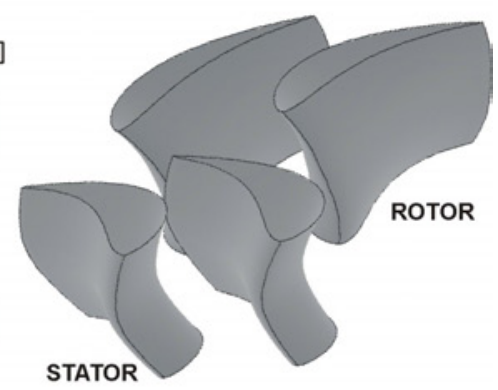

b) Blade geometry

Fig. 3. Representation of the experimental turbine

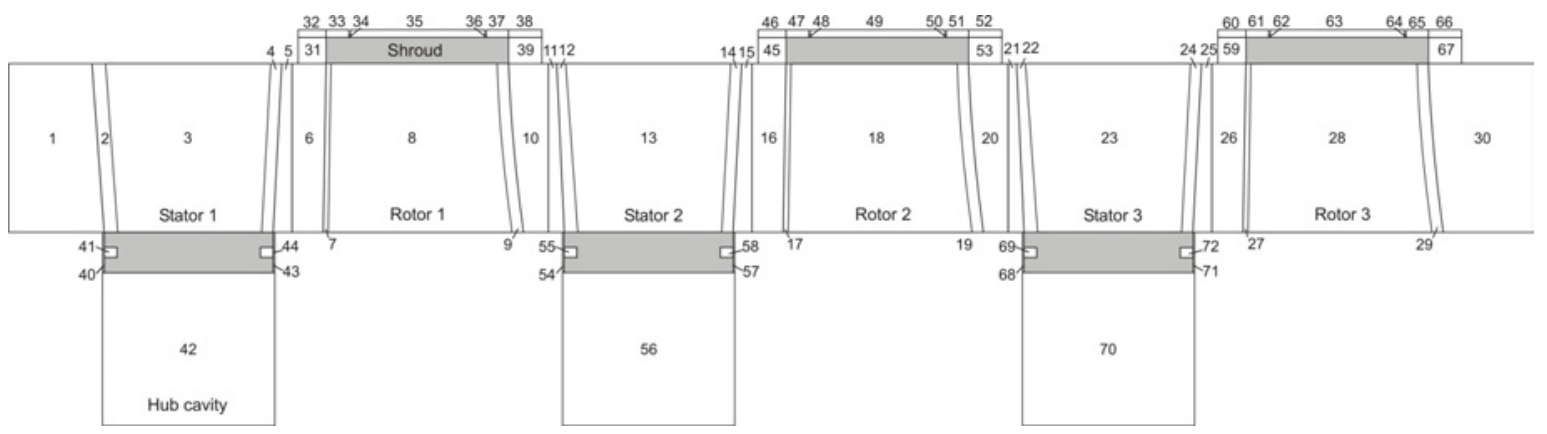

Fig. 4. TBLOCK computational domain

TBLOCK can be run in parallel with domain decomposition done on a block basis.

The code is aimed at predicting both main blade path and secondary gas path flows in turbomachinery although it can be used to calculate other types of flow. The solver overcomes most of the limitations of the simple shroud leakage model in calculating complex geometries, and was used for the calculations in this paper including the shroud leakage flow path. The flow field is divided into as many 'cuboid' blocks as are necessary to represent the geometry and each block is solved separately. Information passes between blocks using different types of interfaces treated as 'patches' (inlet and exit boundary, solid boundary, mixing plane, periodic boundary). The method is tolerant of extreme levels of grid distortion, and when necessary can interpolate the flow data from one patch onto another, which may lie on a non-contiguous face and may have a different number of grid points.

Four configurations with different radial seals clearance $(0.25,0.50,0.75,1.00 \mathrm{~mm})$ on the shroud cavities for all the three stages were modelled using TLOCK. Simulations were completed modelling all three stages single passage domain, including rotor tip shroud and stator hub leakage paths. Figure 4 presents the flow domain decomposition.

The domain was divided into 72 blocks. In particular, the leakage flow paths were divided into the necessary number of rectangular blocks using structured $\mathrm{H}$ meshes. Two different levels of mesh refinement were analysed. For the finer mesh, the main blade passage was modelled using 124 grid points in the axial, and 114 grid points in both pitch-wise and radial directions (Fig. 5). The whole domain consists of 36.89 million grid points. The coarser mesh adopted 99 grid points in the axial direction and 91 points in pitch-wise and radial directions, for a total of 18.92 million computational nodes.

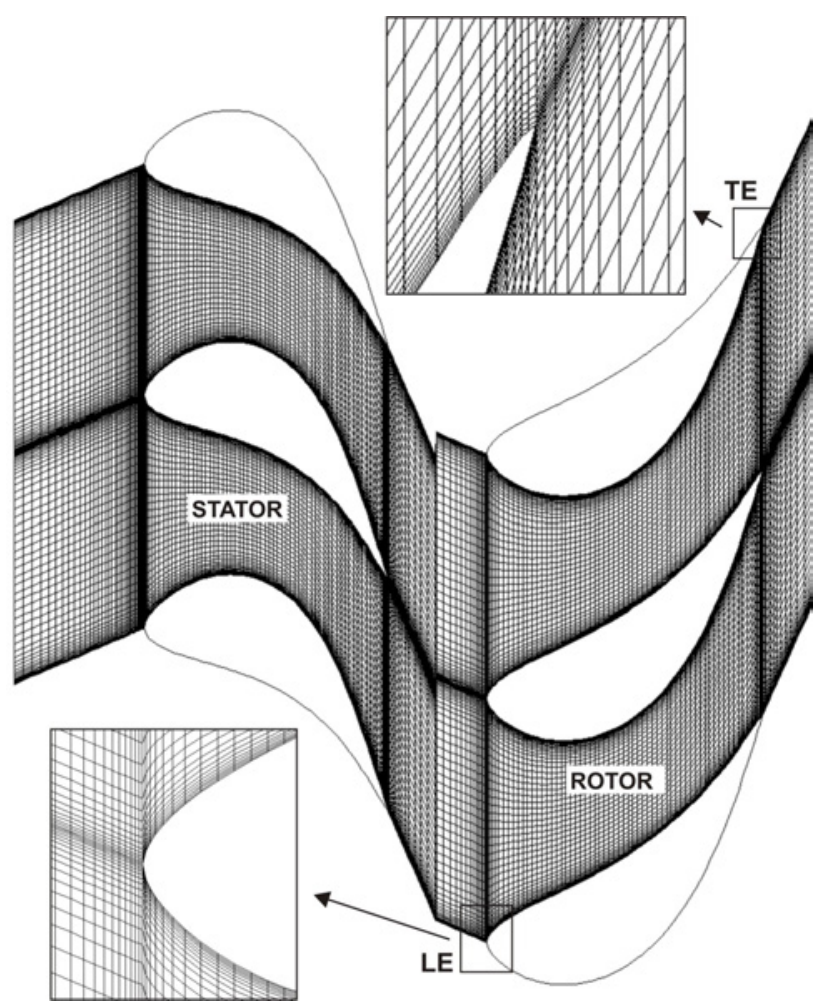

Fig. 5. TBLOCK computational grid 


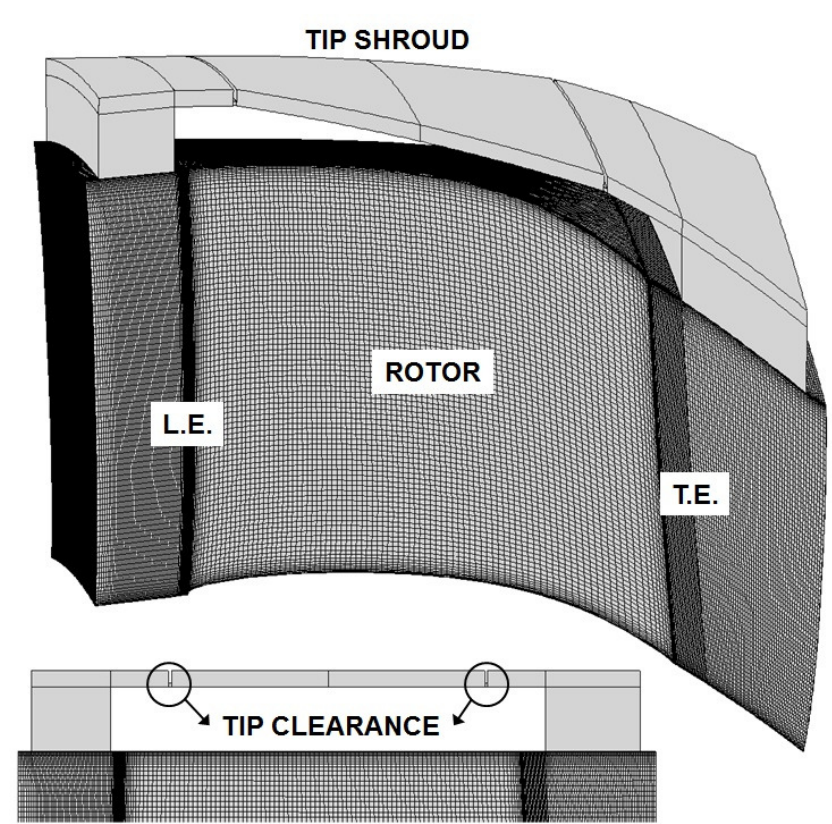

Fig. 6. TBLOCK - rotor and tip shroud grid structure

The simulation was run in parallel using 72 processors. A fully converged unsteady solution initialised from previous steady computations was obtained for 10 blade-to-vane passes. Averaging of the flow variables was then conducted for a further 10 blade-to-vane passes. The computational time required to complete one blade-to-vane pass for the finer mesh was about 7 hours.
The detailed grid and block structure used to model each rotor blade passage is presented in figure 6 . The rotor tip shroud for all the configurations under scrutiny was modelled with different radial clearance gaps reproduced for every stage.

\section{NUMERICAL RESULTS}

\subsection{Comparison with experiments}

In comparing calculated and measured flow patterns it must be remembered that the real clearance is not known with great accuracy and that it varies significantly around the circumference. In the experimental configuration, the shroud forms a radial clearance of $3 \mathrm{~mm}$ with the casing and the average radial gap for seals is assumed to be $0.75 \mathrm{~mm}$.

Predicted distributions of total pressure coefficient downstream of the second and third stators and their comparison with experimental results are shown in Fig. 6. Both pitch-wise averaged profiles (left) and 2-D contour map (right) are presented. The measurement plane covers one pitch from $3 \%$ to $95 \%$ span. As it can be observed on the pitch-wise averaged profiles, numerical simulations on both coarse and fine mesh well reproduce the pressure levels and the main trend along the span. A comparison between 2-D contours show that TBLOCK calculations captured reasonably well the main flow features, such as the locations and intensity of the main loss core and of the hub end-wall secondary flow, and the migration towards the mid-span of the concentrated low momentum flow associated with casing end-wall boundary layers and leakage.
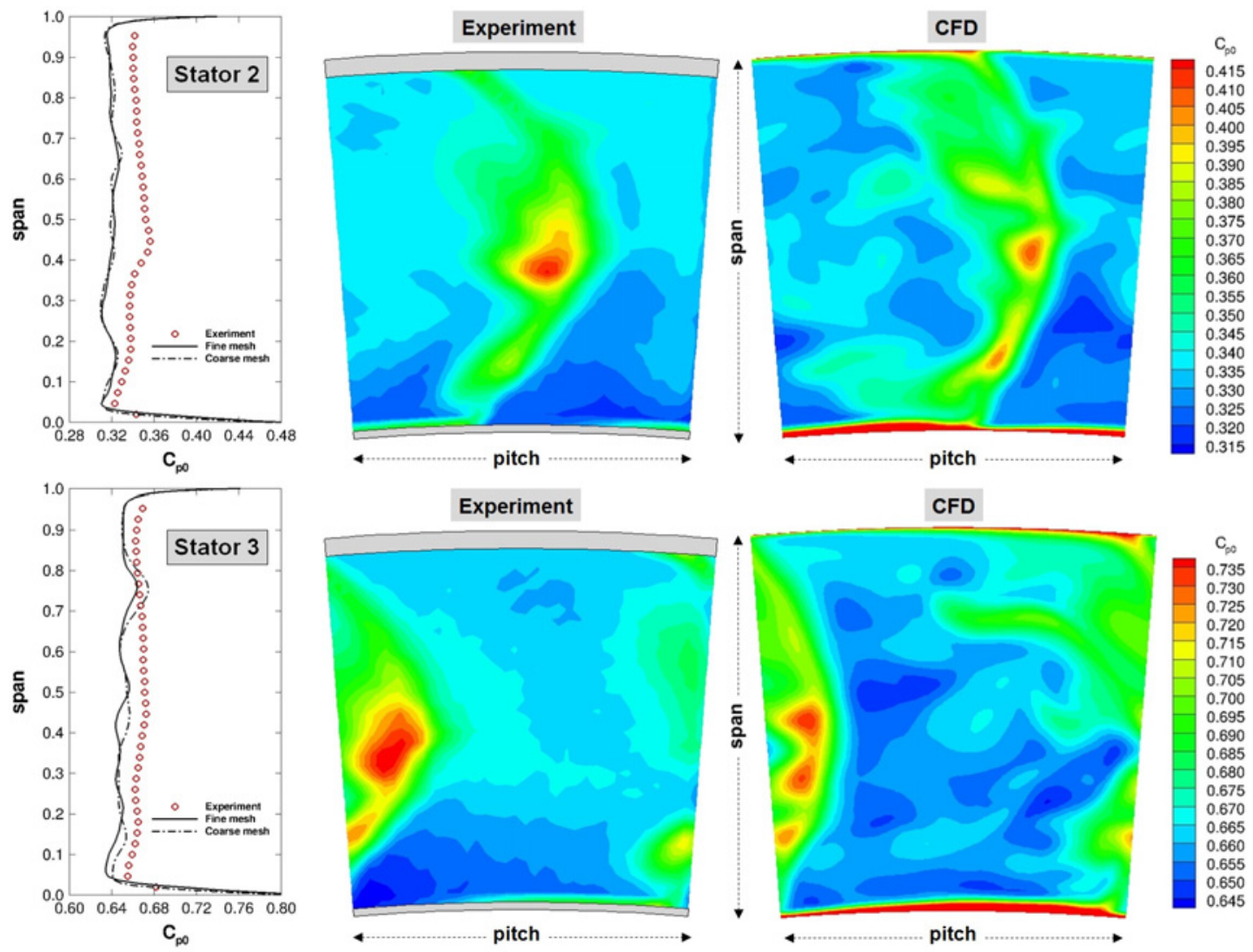

Fig. 7. Measured and predicted total pressure coefficient downstream stator $2 \& 3$ 

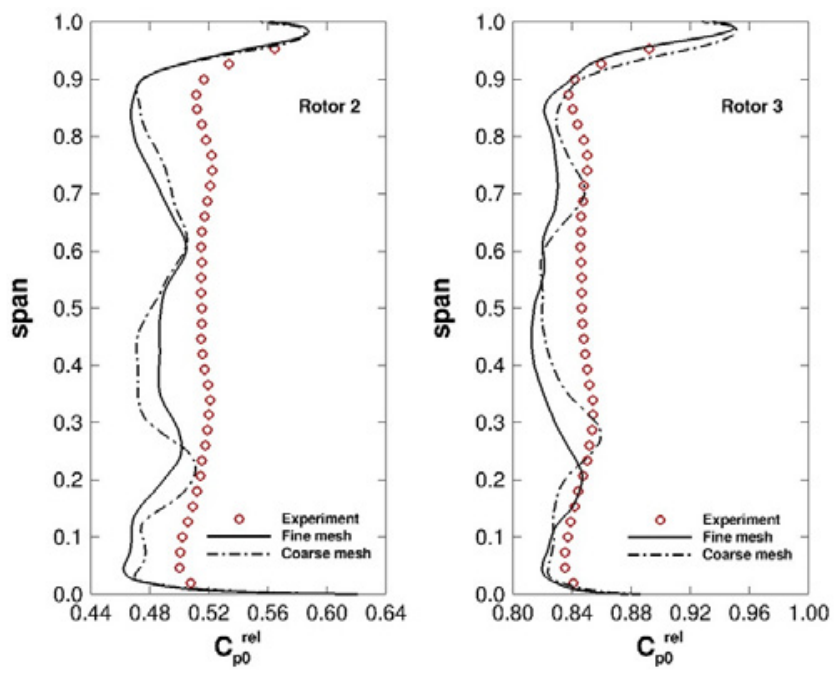

Fig. 8. Measured and predicted pitch-wise averaged total pressure coefficient downstream rotor $2 \& 3$
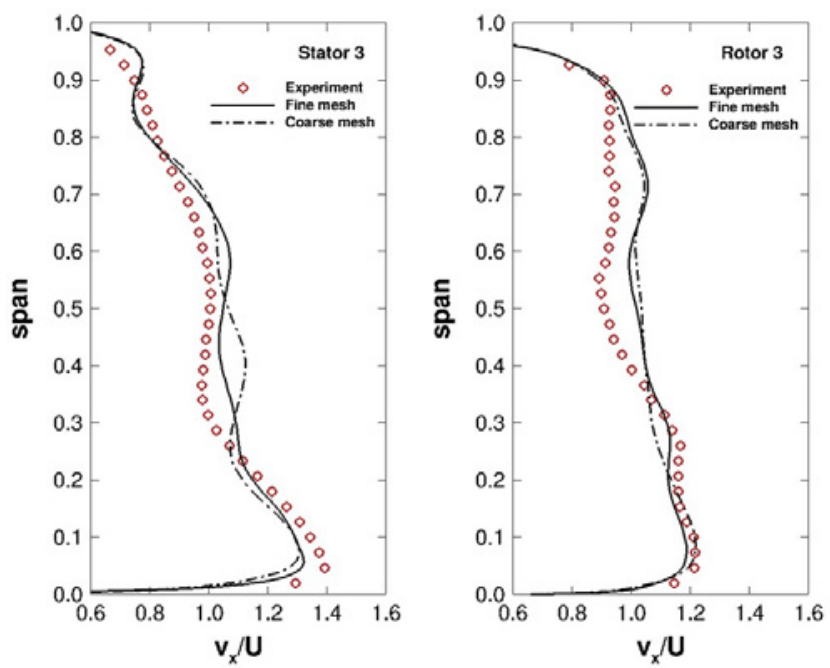

Fig. 9. Measured and predicted pitch-wise averaged axial velocity downstream stator $3 \&$ rotor 3
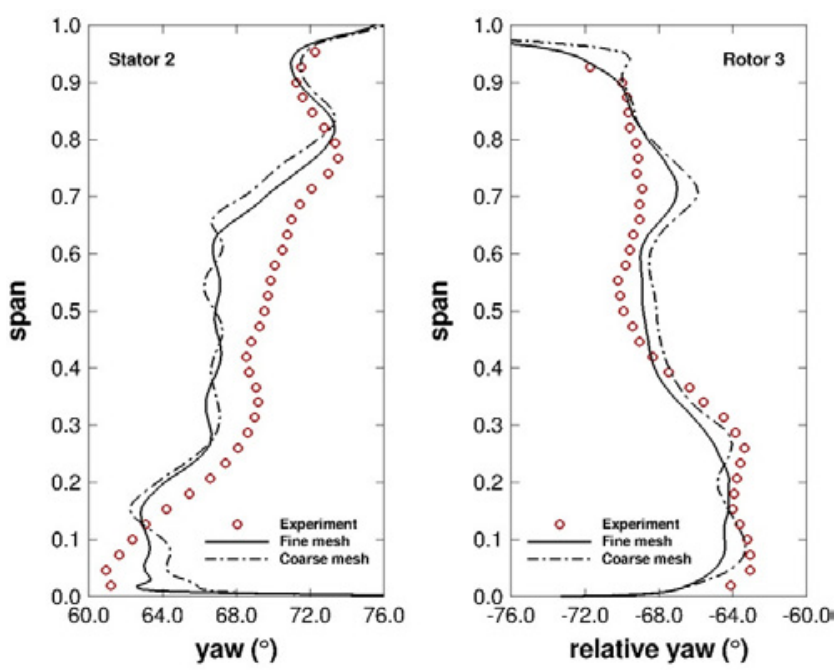

Fig. 10. Measured and predicted pitch-wise averaged yaw angle downstream stator $2 \&$ rotor 3

Comparisons between experimental and numerical pitchwise averaged relative total pressure coefficients downstream the second and third rotor, are reported in Fig. 8. Numerical simulations are able to predict the radial locations of the mid- span and end-walls loss cores, although their levels were slightly overestimated.

Velocity field is analysed in Fig. 9 and 10, which show the span-wise distribution of pitch-wise averaged values of axial velocity (Fig. 9) and yaw angle (Fig. 10) at different downstream stator/rotor locations. Numerical simulations were in good agreement with experimental results in predicting magnitude and directions of the flow downstream both vanes and blades passages. In particular, in the region close to the casing and the shroud exit cavity of the third rotor, TBLOCK was able to reproduce the overturning trend in the main passage flow angle caused by mixing of the leakage flow.
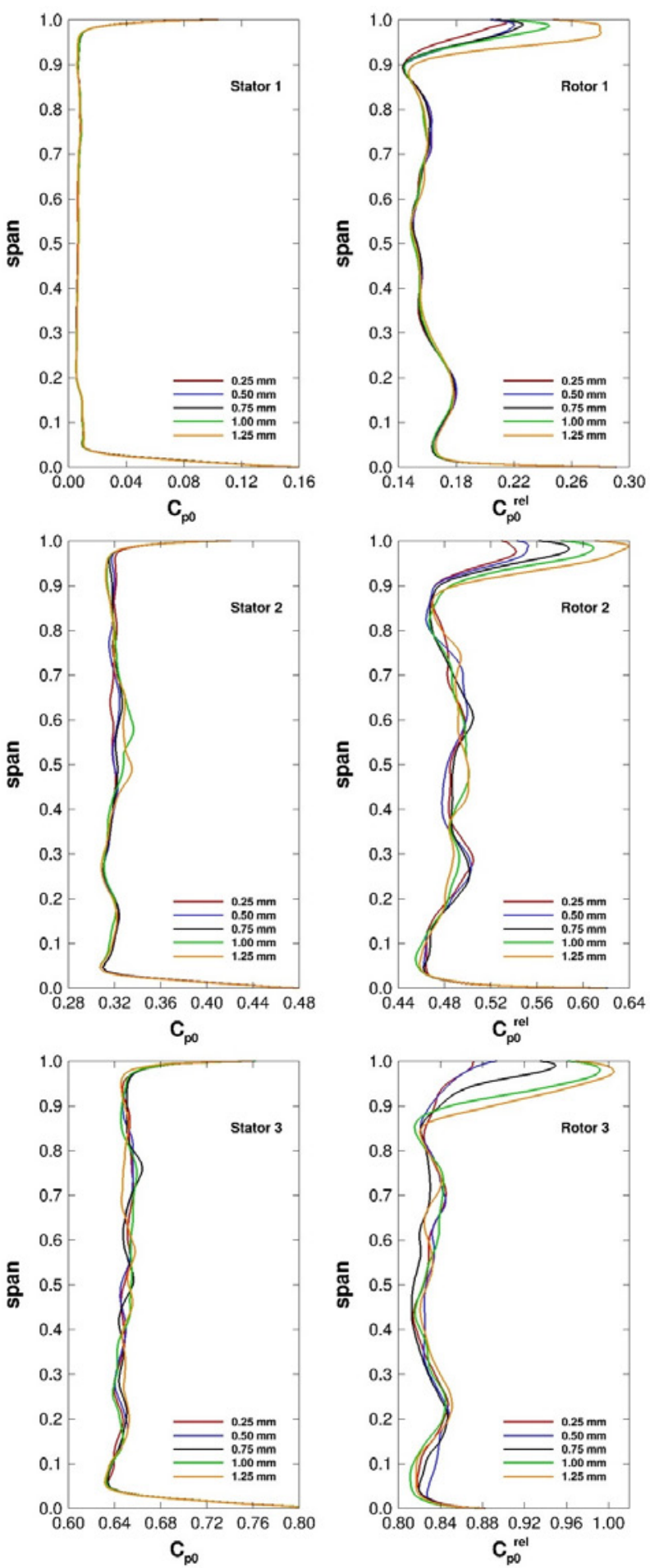

Fig. 11. Predicted pitch-wise averaged total pressure coefficient profiles for different seals clearances 

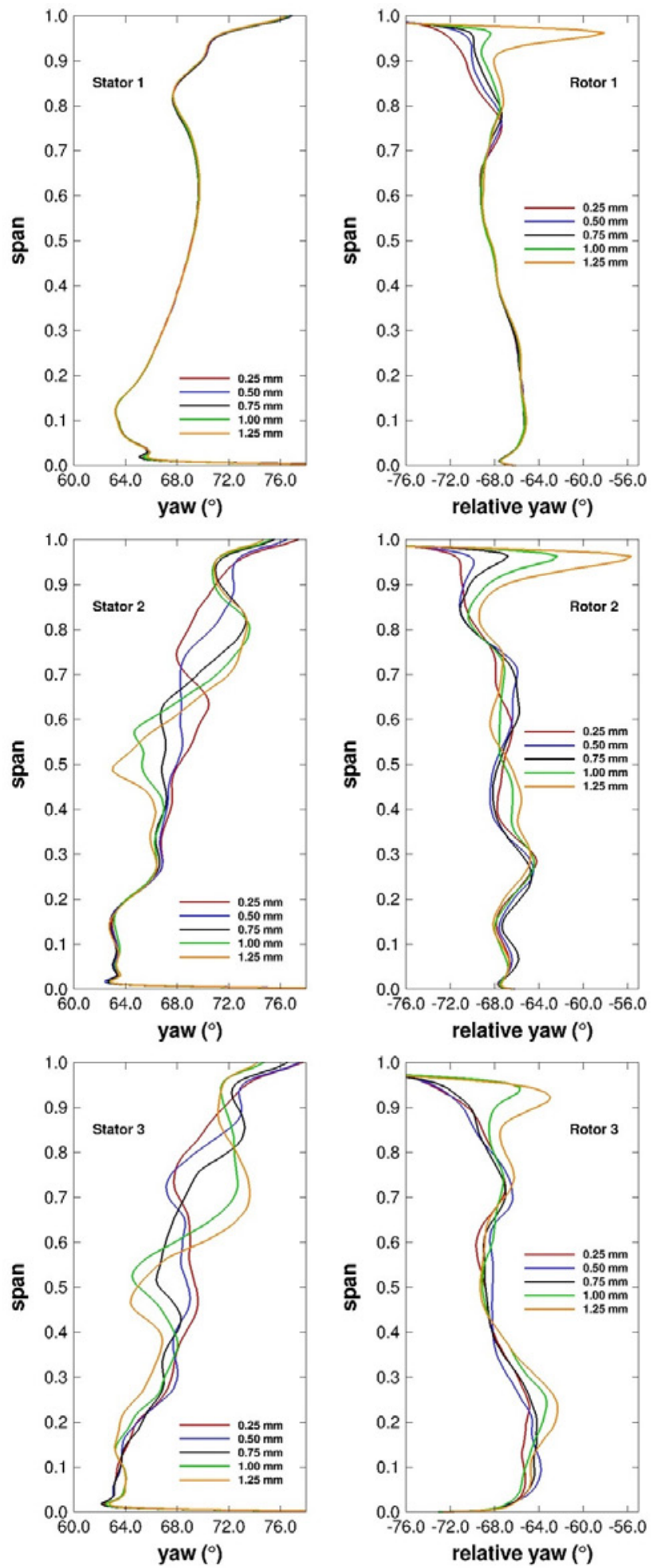

Fig. 12. Predicted pitch-wise averaged yaw angle profiles for different seals clearances

\subsection{Different seals clearance gaps}

According to steam turbine industrial practice, due to manufacturing tolerances and assembly process, real shroud geometry presents some mismatches with their theoretical design and it is also very hard to have a reliable estimation on rotor shroud gap. Furthermore, during long-term turbine operation the sealing effectiveness deteriorates due to rubbing and worn sealing elements. Because of this, leakage fractions for shrouded blades can vary from $1 \%$ to $4 \%$ within $\mathrm{HP}$ turbines [14]. Therefore it is important to investigate the
Article Title -6

influence of the different shroud radial gap on the main blade path. This was done in a numerical study using the same numerical flow domain as in the first part of this section varying the seal clearance over both radial fins simultaneously while the datum shroud geometry was kept unchanged.

The variations of pitch-wise averaged total pressure coefficient and yaw angle distributions with clearance gap are reported in Figures 11 and 12, respectively. Absolute and relative values are shown at stators exits (the left sides) and downstream the rotors (right side), respectively.

It is worthwhile noting how the flow field in the exit rotor shroud cavity is greatly affected by the leakage jet generated in the upstream seal gap and re-entering the main passage. The leakage flow fraction is enhanced with increasing clearances, causing higher pressure losses near the casing (Fig. 9, right side). Also, as the clearance increases, the leakage jet increases its momentum (Fig. 11, right side), forming a region of higher relative yaw angle in the near casing of the main annulus (Fig. 12 , right side), because of mechanism explained in [14].

The negative influence of the leakage flow on the flow field in the downstream blade row can be observed on the left side of Fig. 12, by analysing the yaw angle distributions downstream the stators exits. The leakage flow caused a strong underturning of the flow at the mid-span, and also the ' $\mathrm{S}$ ' shape angle distribution close to the casing, associated with the casing secondary flows, was enhanced.

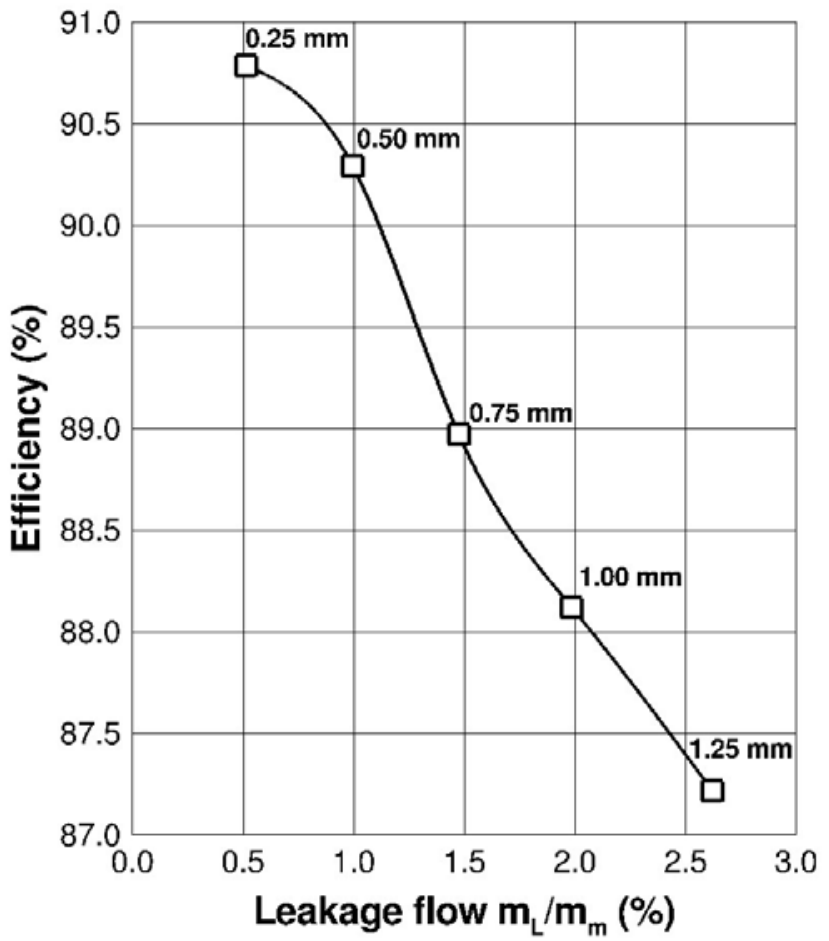

Fig. 13. Change in turbine efficiency with leakage fraction

Finally, the influence of leakage flow on the mainstream flow in the three stage turbine analysed in this paper can be summarized in the diagram of Fig. 13, which shows the changes in turbine efficiency with leakage fraction. He resulting trend is in agreement with the classical shroud leakage theory which assumes that the loss in efficiency associated with leakage flow is directly proportional to the leakage flow rate 


\section{UNCERTAINTY QUANTIFICATION}

A basic method to obtain the stochastic distributions of output variables like the stagnation pressure or the yaw angle if the clearance gap varies randomly is the Monte Carlo method. First, a probability distribution must be assumed for the clearance gap. Then, a suitable random number generator is used to create the individual input random samples to follow the prescribed distribution. Finally, the simulation only has to be run repeatedly for every random sample drawn from the PDF. Convergence is achieved by increasing the number of the simulations. Unfortunately, the convergence is slow: the sample size has to be quadrupled every time to half the error. For a cost intensive computational model, as it is the case here, it is therefore prohibitive to use a Monte Carlo method.

In the given simulation, only one random variable is present, the clearance gap, and it can be assumed to be Gaussian. This assumption is made based on the available literature on manufacturing uncertainties, which tend to display Gaussian behaviour [26]. Both assumptions together can be used to achieve an immense cost reduction by using a Non-Intrusive Polynomial Chaos Method: the Probabilistic Collocation Method (PCM) as described in [31].

The underlying idea of all Polynomial Chaos methods is that the functional form of the stochastic outputs of a model can be found with significantly lower computational effort, if they are approximated through a basis of optimal orthogonal polynomials defined through the input random variables. The additional concept of probabilistic collocation is that since the statistical moments are integrals of the output PDFs, they can be cheaply and accurately integrated by using optimal Gaussian quadrature on the found polynomial expansion. In consequence, the model only has to be run a few times using the Gaussian collocation points of the clearance gap to calculate accurate numerical approximations for all output distributions.

The number of the Gaussian collocation points is naturally connected to the polynomial order of the expansion. They are chosen as the roots of the next higher order polynomials. For example, 5 points are needed for a $4^{\text {th }}$ order expansion. Moreover, the number is also dependent on the number of input variables used. Since for multiple input variables the collocation points have to be combined through tensor products, Polynomial Chaos methods become quickly inefficient for increasing numbers of input random variables. For only one input variable, however, five collocation points can achieve an accuracy level comparable a million Monte Carlo runs [31].

\subsection{Probabilistic Collocation Method (PCM)}

The basic concept of Polynomial Chaos expansions can be traced back to Wiener [32], who found that the stochastic output $y(x, \xi)$ of a function can be decomposed into a series with deterministic coefficients $\alpha_{i}(x)$ and stochastic orthogonal polynomials $\psi_{i}(\xi)$, such that:

$$
y(x, \xi) \approx \sum_{i=0}^{N_{p}-1} \alpha_{i}(x) \psi_{i}(\xi)
$$

where $N_{P}$ is a truncation to limit the infinite expansion series.

For the one dimensional case $N_{P}$ can simply be chosen as the maximum polynomial order of the chosen expansion plus one. Moreover, $\xi$ is a Gaussian random variable representing the clearance gap, and $y$ is representative for either the stagnation pressure ot the yaw angle.

For a Gaussian random variable, the optimal orthogonal polynomials $\psi_{i}(\xi)$ are the Hermite polynomials [33]. The choice of the polynomials is always a consequence of the probability distribution of the inputs variables. Thus, only the coefficients $\alpha_{i}(x)$ are unknown. In order to find these, a linear system of $N_{p}$ equations can be solved in the optimal Gaussian collocation points $\xi_{i}$ :

$$
\left[\begin{array}{ccc}
\psi_{0}\left(\xi_{0}\right) & \cdots & \psi_{P}\left(\xi_{0}\right) \\
\vdots & \ddots & \vdots \\
\psi_{0}\left(\xi_{N_{p}}\right) & \cdots & \psi_{P}\left(\xi_{N_{p}}\right)
\end{array}\right]\left[\begin{array}{c}
\alpha_{0} \\
\vdots \\
\alpha_{N_{P}}
\end{array}\right]=\left[\begin{array}{c}
y\left(x, \xi_{0}\right) \\
\vdots \\
y\left(x, \xi_{N_{p}}\right)
\end{array}\right] \text { Eq.2 }
$$

Here, the clearance gap is chosen as Gaussian random with distribution $N(0.75,0.03356)$. This results in approximate gap widths collocation points $0.25,0.5,0.74,1.00$ and 1.25 as used before and the PDF as shown in Fig. 14.

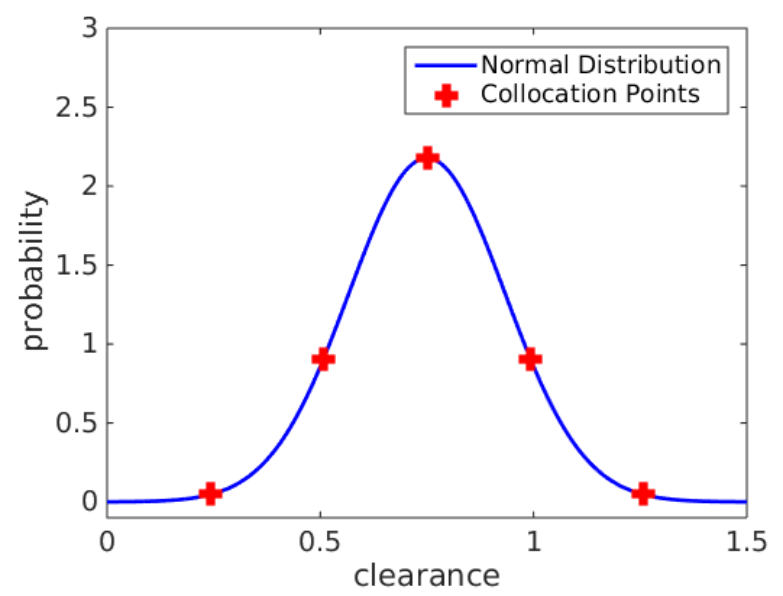

Fig. 14. Probability distribution used as input PDF including optimal Gaussian collocation points.

The mean $\mu_{y}$ and variance $\sigma_{y}^{2}$ of y can then be found using the coefficients by calculating

$$
\mu_{y}=\alpha_{0} \quad \sigma_{y}^{2}=\sum_{i=1}^{N_{p}-1} \alpha_{i}^{2}\left\langle\psi_{i}^{2}\right\rangle
$$

The PDF of $y$ can be illustrated by Monte Carlo sampling the found expansion in eq. 1 using random samples with PDF $N(0.75,0.03356)$. Unlike direct sampling of the CFD model, this sampling process needs negligible computation time. Convergence of the polynomial expansion can be found by increasing the order of the expansion. Here, orders from 3 to 5 were tested. Comparing $4^{\text {th }}$ and $5^{\text {th }}$ order a four decimal accuracy was found so that no higher orders were computed.

\subsection{Results}

Figure 15 shows the pressure coefficient distribution at the exit of each row. The dashed red line is the standard deviation. The uncertainty bars represent one standard deviation superimposed on the mean pressure distribution. 

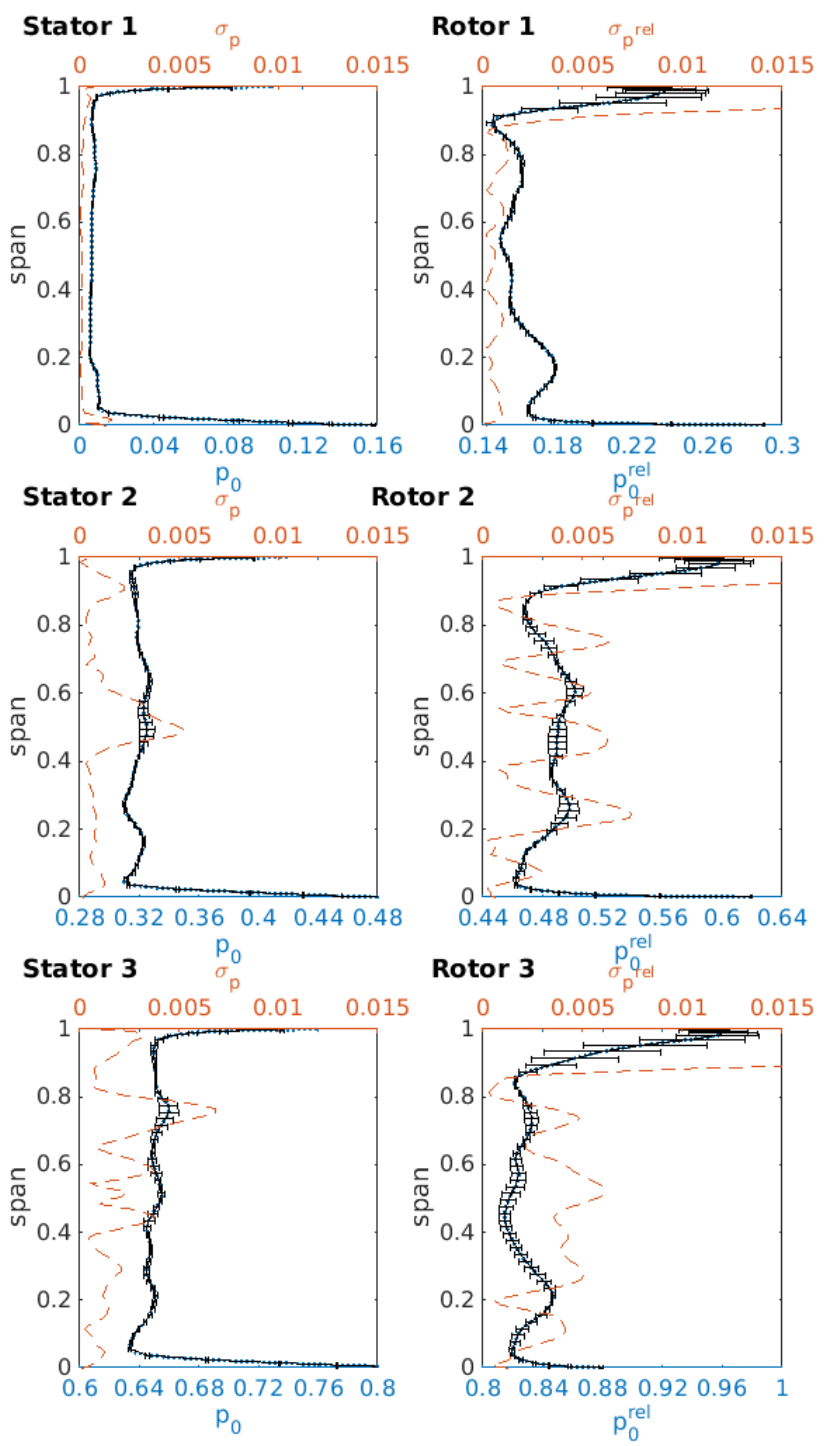

Fig. 15. Stagnation pressure coefficient distribution and uncertainty

In the first stage we can observe that the impact of uncertainty in the rotor tip is affecting only the higher part of the rotor. Only about 10\% of the span (100-90\%) is influenced by the rotor tip random variation. Similarly large random variation in this region can be observed for rotor 2 and rotor 3 as well. For the second stator, the peak of uncertainty is surprisingly at $50 \%$ and the region between $40 \%$ and $60 \%$ of the span is mostly affected. For the second rotor, the entire span is affected. In the last stage, the standard deviation for the stator peaks at $78 \%$, with a region of increased variation higher between 65 and $80 \%$. The last rotor is most strongly affected by the uncertainty with a strong variation from 20 to $80 \%$.

There are different mechanisms involved. The changes in rotor tip gaps modifies the mass flow distribution and this alter the radial uncertainty. At the same time, the impact of the leakage flows modifies the work carried out by the rotor due to the variation of the inlet (and exit) angle. This is clearly shown in figure 16 where the exit angles indicates the variation in load associated to each row.

It is important to notice that the found regions with high standard deviation agree with the regions in which the CFD results differed largely from the experimental in the original work of Rosic et al [12]. The performed uncertainty quantification study therefore gives suggest a reason of this disagreement between CFD and experiments: it can be associated to a small variation of the tip gap in the machine that is different from the CFD model.
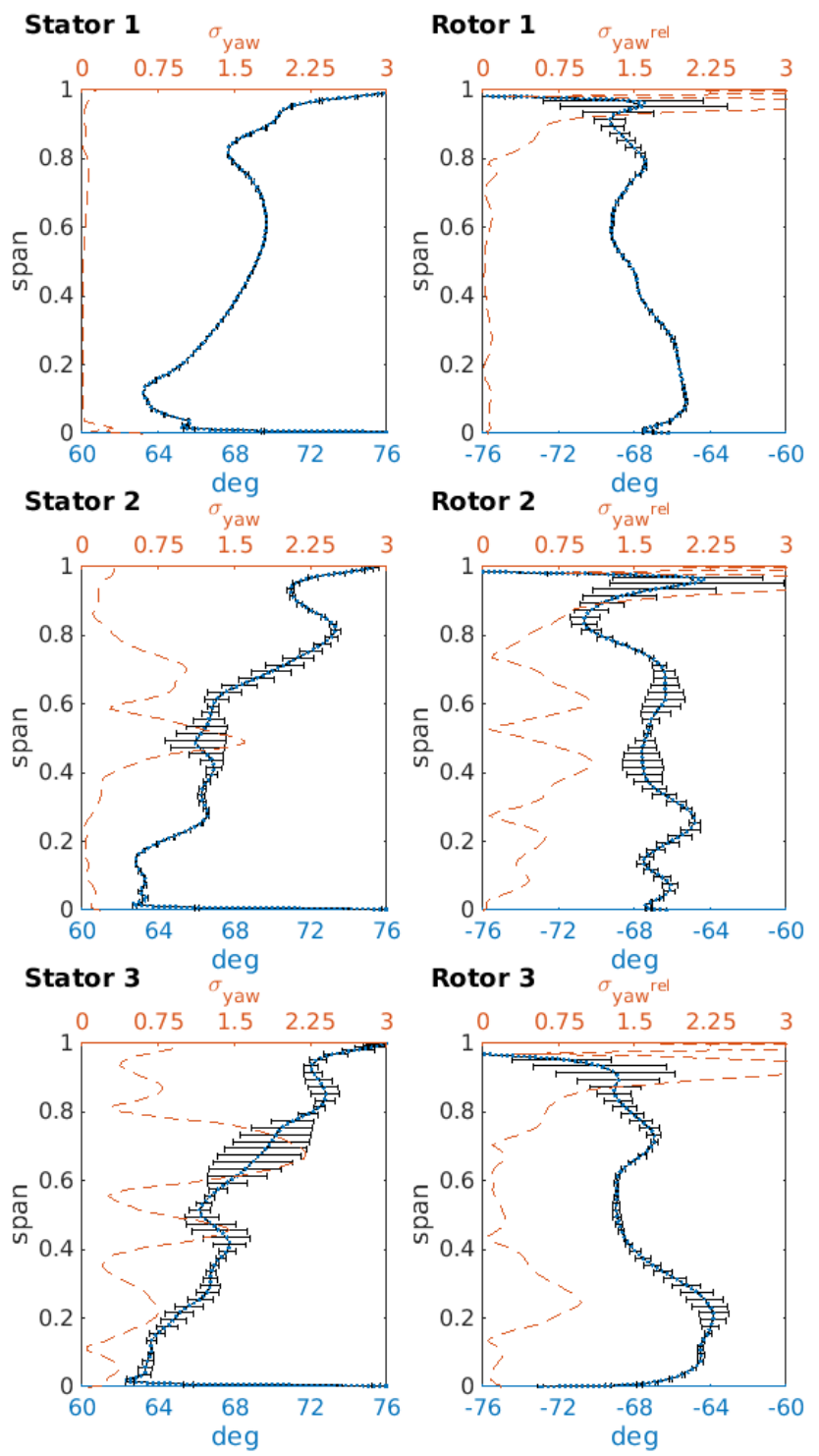

Fig. 16. Yaw angle variation and standard deviation superimposed

\section{REFERENCES}

1. Wallis, A. M., "Secondary and Leakage Flows in a Multistage Turbine", PhD Thesis, Cambridge University Engineering Department, 1997.

2. Pfau, A., Treiber, M., Sell, M., Gyarmathy, G, "Flow Interaction From the Exit Cavity of an Axial Turbine Blade Row Labyrinth Seal", Transaction of the ASME, Journal of Turbomachinery., 2001, Vol. 123, pp. 342-352.

3. Rushton, G. J., "High-Pressure Turbine Shroud Leakage, PhD Thesis", Cambridge University Engineering Department, 2003.

4. Giboni, A., Menter., J. R., Peters, P., Wolter, K., Pfost, H., Breisig, V., "Interaction of Labyrinth Seal Leakage Flow and Main Flow in an Axial Turbine", ASME Paper GT2003- 
38722, 2003.

5. Metzger, D. E., Rued., K., "The Influence of Turbine Clearance Gap Leakage on Passage Velocity and Heat Transfer Near Blade Tips: Part I-Sink Flow Effects on Blade Pressure Side", Journal of Turbomachinery, 1989, Vol. 111, pp. 284-292.

6. Metzger, D. E., Rued., K., "The Influence of Turbine Clearance Gap Leakage on Passage Velocity and Heat Transfer Near Blade Tips: Part II-Source Flow Effects on Blade Suction Sides", Journal of Turbomachinery, 1989, Vol. 111, pp. 293-300.

7. Anto, K., Xue, S., Ng, W. F., Zhang, L. J., Moon, H. K., "Effects of Tip Clearance Gap and Exit Mach Number on Turbine Blade Tip and Near-Tip Heat Transfer", ASME Paper No. GT2013-94345, 2013.

8. Traupel, W., "Erbenisse von Turbinenversuchen", From: Flow Research on Blading, Elsvier, 1970.

9. Denton, J. D., Johnson, C. G., "The Tip Leakage Loss of Turbine Blades - A Review and a Theory for Shrouded Blades", CEGB Report No R/M/N627, Marchwood Engineering Laboratories, 1972.

10. Denton, J. D., "Loss Mechanisms in Turbomachines", ASME Paper 93-GT-435, 1993.

11. Gier, J., Stubert, B., Brouillet, B., de Vito, L., "Interaction of Shroud Leakage Flow and Main Flow in a Three-Stage LP Turbine", ASME Paper GT2003-38025, 2003.

12. Rosic, B., Denton, J. D., Pullan, G., "The Importance of Shroud Leakage Modelling in Multistage Turbine Flow Calculations", ASME Paper GT2005-68459, 2005.

13. Rosic, B., Denton, J. D., "The Control of Shroud Leakage Loss by Reducing Circumferential Mixing", ASME Paper GT2006-90946, 2006.

14. Rosic, B., Denton, J. D., Curtis, E. M., "The Influence of Shroud and Cavity Geometry on Turbine Performance An Experimental and Computational Study, Part 1: Shroud Geometry", ASME Paper GT2007-27769, 2007.

15. Rosic, B., Denton, J. D., Curtis, E. M., Peterson, A. T., "The Influence of Shroud and Cavity Geometry on Turbine Performance - An Experimental and Computational Study, Part 2: Exit Cavity Geometry", ASME Paper GT2007-27770, 2007.

16. Fadlun E. A., Michelizzi I. De laco M., "Measurement error influence on gas turbine operability for conditionbased maintenance and reliability/availability improvement", ASME Paper GT2008-50749, 2008.

17. Williams, D. T., Smout, P., Bianchi, M., Joinson, M. B., "The Use of Probabilistic Methods in Determining Turbine Disc Cyclic Life Uncertainty", ASME Paper GT2013-94972, 2013.

18. Bunker R.S. "The Effect of Manufacturing Tolerances on Gas Turbine Cooling", Journal of Turbomachinery, 2009, vol. 131, pp. 41018-41018-11.
19. D'Ammaro A, Montomoli F.: "Uncertainty Quantification and Film Cooling", Journal of Computer and Fluids, 2013, Vol:71, pp.320-326.

20. Montomoli, F., Carnevale, M., D’Ammaro, A., Massini, M., \& Salvadori, S. (2015). Uncertainty Quantification in Computational Fluid Dynamics and Aircraft Engines. Springer.

21. Carnevale M., Montomoli F., D’Ammaro A., Salvadori, F Martelli, "Uncertainty Quantification: A Stochastic Method for Heat Transfer Prediction Using LES", Journal of Turbomachinery, 2013, doi: 10.1115/1.4007836.

22. Montomoli F., D’Ammaro A, Uchida S.: “Uncertainty Quantification and Conjugate Heat Transfer: a Stochastic Analysis", Journal of Turbomachinery, 2013.

23. Montomoli F, M. Massini, S. Salvadori: "Geometrical Uncertainty in Turbomachinery": International Journal of Computer and Fluids, Elsevier, 2010.

24. Büche, D., Beetz, M., Ribi, B., \& Turbo, M. A. N. (2010). "Uncertainty Analysis for large-scale industrial radial compressors", ASME paper GT2010-22918, 2010.

25. De Maesschalck, C., Lacor, C., Paniagua, G., "Performance Robustness of Turbine Squealer Tip Designs due to Manufacturing and Engine Operation". In ISABE conference paper, 2015.

26. Panizza, A., Bonini, A., Innocenti, L., "Uncertainty Quantification of Hot Gas Ingestion for a Gas Turbine", ASME paper GT2015-42679, 2015.

27. Wunsch, D., Hirsch, C., "Quantification of Combined Operational and Geometrical Uncertainties in TurboMachinery Design", ASME paper GT2015-43399, 2015.

28. Rosic, B., "The Control of Shroud Leakage Flows in Low Aspect Ratio Multistage Turbines", PhD Thesis, Cambridge University Engineering Department, 2006.

29. Denton, J. D., "TBLOCK Manual”, 2002.

30. Denton, J. D., "The Calculation of Three Dimensional Viscous Flow Through Multistage Turbomachines", ASME Paper 90-GT-19, 1990.

31. Hosder, S., Walters, R. W., "Non-intrusive polynomial chaos methods for uncertainty quantification in fluid dynamics", 48th AIAA Aerospace Sciences Meeting, January 2010.

http://arc.aiaa.org/doi/pdf/10.2514/6.2010-129

32. Wiener, N., "The Homogeneous Chaos". American Journal of Mathematics, 1938, Vol. 60, pp. 897-936

33. Xiu, D., \& Karniadakis, G. E., "Modeling uncertainty in flow simulations via generalized polynomial chaos", Journal of Computational Physics, 2003, Vol. 187, pp. 137-167. 